\title{
Variation of Main Phenophases in Phenological Calendar in East China and Their Response to Climate Change
}

\author{
Fengyi Zheng, ${ }^{1,2}$ Zexing Tao, ${ }^{1,2}$ Yachen Liu, ${ }^{1,3}$ Yunjia Xu, ${ }^{1,2}$ Junhu Dai, ${ }^{1}$ and Quansheng Ge \\ ${ }^{1}$ Key Laboratory of Land Surface Pattern and Simulation, Institute of Geographical Sciences and Natural Resources Research, \\ Chinese Academy of Sciences, Beijing 100101, China \\ ${ }^{2}$ University of Chinese Academy of Sciences, Beijing 100049, China \\ ${ }^{3}$ School of Geography, Beijing Normal University, Beijing 100875, China
}

Correspondence should be addressed to Junhu Dai; daijh@igsnrr.ac.cn and Quansheng Ge; geqs@igsnrr.ac.cn

Received 18 March 2016; Accepted 26 June 2016

Academic Editor: Gang Liu

Copyright (C) 2016 Fengyi Zheng et al. This is an open access article distributed under the Creative Commons Attribution License, which permits unrestricted use, distribution, and reproduction in any medium, provided the original work is properly cited.

Based on the phenological data from China Phenological Observation Network, we compiled the phenological calendars of 3 phenological observation stations (Shanghai, Nanjing, and Hefei) in East China for 1987-1996 and 2003-2012 according to the sequences of mean phenophases. We calculated the correlated coefficient and the root mean square error (RMSE) between phenophases and the beginning of meteorological seasons to determine the beginning date of phenological season. By comparing new phenological calendars with the old ones, we discussed the variation of phenophases and their responses to temperature. The conclusions are as follows. (1) The beginning dates of spring and summer advanced, while those of autumn and winter delayed. Thus, summers got longer and winters got shorter. (2) The beginning time of the four phenological seasons was advancing during 1987-1996, while it was delaying during 2003-2012. (3) Most spring and summer phenophases occur earlier and most autumn and winter phenophases occur later in 2003-2012 than in 1987-1996. (4) The beginning time of phenological seasons was significantly correlated with temperature. The phenological sensitivities to temperature ranged from -6.49 to -6.55 days $/{ }^{\circ} \mathrm{C}$ in spring, -3.65 to -5.02 days $/{ }^{\circ} \mathrm{C}$ in summer, 8.13 to 10.27 days $/{ }^{\circ} \mathrm{C}$ in autumn, and 4.76 to 10.00 days $/{ }^{\circ} \mathrm{C}$ in winter.

\section{Introduction}

Phenology is the study of periodic biological events affected by environment $[1,2]$. Besides instrumental measurements, phenology can also reflect the impacts of climate change on the biological and physical systems independently [3] and is regarded as the fingerprints of global warming [4].

Phenological calendar is a specialized calendar recording the sequence of phenological events, which is defined as lists of the starting dates and selected statistics of the phenological phases, their duration, and the intervals between them [5]. The major usage of phenological calendars is to generate a graphically designed phenological spectrum and to study the mean values of records [6]. It is of important value to guide agricultural activities and tourism management $[7,8]$. Phenological calendar can also provide a valuable database for dividing phenological seasons. As one of the effective ways to divide the seasons, phenological season is defined by the sequence of various phenophases in a year. The phenological season is objective to embody the seasonal alternations because phenological phenomena could indicate the changes in climate and environment $[5,6]$. Wan $[8,9]$ set a standard to divide one year into 4 phenological seasons (spring, summer, autumn, and winter) and compiled the phenological calendar of the cities in China Phenological Observation Network (CPON) during 1963-1985. However, with climate warming, the timing of phenophases in recent years has evidently shifted $[10,11]$. Therefore, it is necessary to compile new phenological calendars to reflect the phenological characters in different regions. To date, people have compiled new phenological calendars in Beijing and Harbin, China [12,13], but the work in other regions was not reported. In addition, previous phenological studies mainly focused on phenological variation in temperate regions at middle and high latitudes and revealed that most of the spring phenophases advanced while phenophases in autumn 
TABLE 1: Geographical information of the 3 phenological observation stations.

\begin{tabular}{lccccc}
\hline Station & Longitude $\left({ }^{\circ} \mathrm{E}\right)$ & Latitude $\left({ }^{\circ} \mathrm{N}\right)$ & Sea level $(\mathrm{m})$ & Number of species & Number of phenophases \\
\hline Shanghai & 121.48 & 31.22 & 4 & 14 & 35 \\
Nanjing & 118.78 & 32.04 & 9 & 45 & 344 \\
Hefei & 117.25 & 31.83 & 30 & 20 & 136 \\
\hline
\end{tabular}

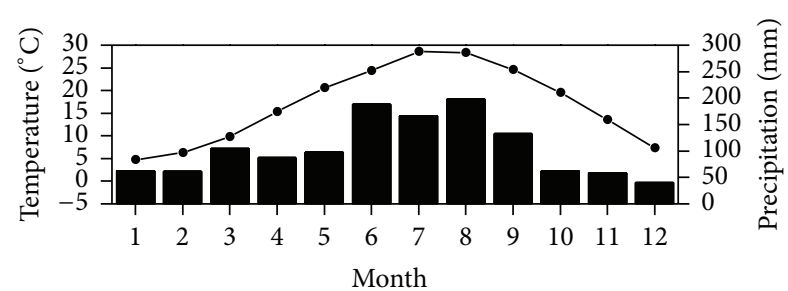

(a)

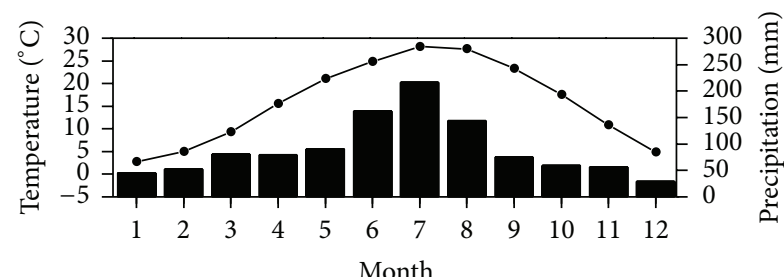

(b)

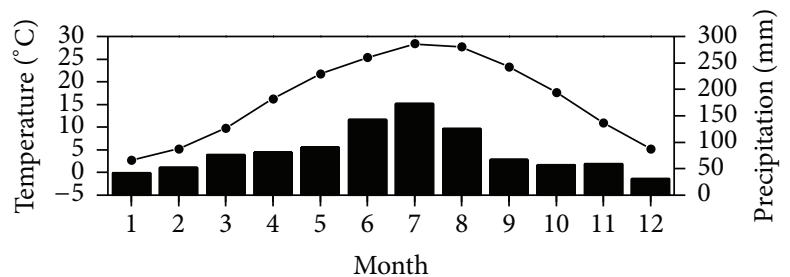

(c)

FIGURE 1: Annual mean temperature and average annual precipitation of the 3 stations (1987-2012). (a) Shanghai; (b) Nanjing; and (c) Hefei. The curves stand for monthly mean temperature, and the bars stand for monthly mean precipitation.

tended to delay in China [13-16] and other places in Northern Hemisphere [17-21]. Nevertheless, few of them discussed the timing and variations of phenology in subtropical areas. As a result, further studies are essential for the completion of the phenological calendar and better understanding of the climatic impact on vegetation phenology in these regions.

We conducted this study in East China, which is located at the margin of subtropical humid monsoon zone and temperate monsoon zone. In this region, phenological observations are organized by CPON since 1963, which provides sufficient data for phenological calendar compilation. Firstly, we used the phenological records from CPON in three representative stations, Shanghai, Nanjing, and Hefei, to compile the phenological calendars for 1987-1996 and 2003-2012. Secondly, we determined the beginning times of phenological seasons for each year and analyzed their trends for the two periods separately. Then, the differences of the mean phenophases between the two periods were calculated to discuss the phenological variations. Finally, we applied linear correlation analysis to study the climatic impacts on plant phenology. This study intends to provide theoretical and data basis for a better understanding of the biological response to regional climate change.

\section{Materials and Methods}

2.1. Study Area. The three stations are located in central of East China with typical subtropical climate and zonal vegetation of evergreen and deciduous broadleaved mixed forest and evergreen broadleaf forest [22]. The annual mean temperature is 19.1 to $20.3^{\circ} \mathrm{C}$. Average annual precipitation is 1000.8 to $1259.3 \mathrm{~mm}$. We selected three phenological observation stations in this area: Shanghai, Nanjing, and Hefei (Table 1), all located in the Middle-Lower Yangtze Plain. The phenological data of the 3 stations were the most complete among the stations in East China. The climate condition of the 3 stations could also represent the climate features of the study area (Figure 1).

2.2. Phenological and Meteorological Data. The phenological data in this paper were from China Phenological Observation Network (CPON), a nationwide system of phenological observation stations administered by the Institute of Geographic Sciences and Natural Resources Research (IGSNRR), Chinese Academy of Sciences. We divided the study period into two parts, 1987-1996 and 2003-2012, choosing 11 major phenophases, namely, bud expansion (BE), bud burst (BB), first flowering (FF), $50 \%$ of full flowering $(50 \mathrm{~F})$, end of flowering (EF), first leaf (FL), 50\% of full leaf expansion (50L), beginning of leaf coloring (BLC), end of leaf coloring (ELC), beginning of leaf fall (BLF), and end of leaf fall (ELF).

The meteorological data were from China Meteorological Administration (http://data.cma.cn/). We used the daily mean air temperature at the above-mentioned 3 stations from 1987 to 2012 to determine the beginning time of the four meteorological seasons and carry on linear correlation analysis between phenophases and temperatures.

2.3. Methods. Based on phenological data referred to above, we listed the phenophases of the 3 stations. For each station, 
TABLE 2: Temperature standard for four meteorological seasons.

\begin{tabular}{lcccc}
\hline Season & Spring & Summer & Autumn & Winter \\
\hline Standards & Above $3^{\circ} \mathrm{C}$ & Above $19^{\circ} \mathrm{C}$ & Below $19^{\circ} \mathrm{C}$ & Below $10^{\circ} \mathrm{C}$ \\
\hline
\end{tabular}

we selected phenophases with 3 or more observation records during each 10-year period and neglected the rest. Then, we calculated the mean dates of the selected phenophases and sorted them according to their sequence to compile the phenological calendars.

According to the division method proposed by Wan [8] (Table 2), we divided each year into 4 meteorological seasons. After 10 consecutive days in which the temperature reached the referential standard, we determined the first day of the 10 consecutive days as the beginning time of the season.

In order to decide the beginning time of the four phenological seasons, the correlated coefficients and the root mean square error (RMSE) between each phenophase and the beginning of corresponding meteorological season were calculated (see (1)), and the phenophases which had the maximum correlation coefficients and minimum RMSE value were chosen as the beginning time of the four phenological seasons:

$$
\mathrm{RMSE}=\sqrt{\frac{1}{n} \sum_{i=\mathrm{YF}}^{\mathrm{YL}}\left(\mathrm{DP}_{i}-\mathrm{DM}_{i}\right)^{2}}
$$

In the equation, $i, \mathrm{YF}, \mathrm{YL}, n, \mathrm{DP}_{i}$, and $\mathrm{DM}_{i}$ represent the year, the first year of calculation, the last year of calculation, the quantity of years with observation records, the date of phenophases in year $i$, and the beginning date of meteorological season in year $i$, respectively.

Subsequently, we compared the beginning time and its trend, as well as the length of the phenological seasons for the two periods.

After that, in order to verify whether the phenophases in spring and summer tended to advance and the phenophases in autumn and winter tended to delay, we calculated the differences between mean phenophases in phenological calendar for the two periods of each station.

Finally, linear correlation analysis between the beginning time of phenological season and the mean temperature in the previous 60 days during the whole period 1987-2012 was carried out to reveal the response of phenophases to climate change.

\section{Results}

3.1. The Beginning Time and Length of Phenological Seasons. By compiling phenological calendars (Appendix, in Supplementary Material available online at http://dx.doi.org/10.1155/ 2016/9546380) of the 3 stations, the beginning time of the four phenological seasons was determined. In all the three stations, spring and summer started earlier in 2003-2012 than in 1987-1996, with the beginning time of spring advancing by 3,1 , and 2 days and that of summer advancing by 5,1 , and 8 days in Shanghai, Nanjing, and Hefei, respectively (Table 3). However, autumn and winter in the three stations started later in the latter period than in the former period, and the beginning time of autumn delayed by 16 days, 2 days, and 1 day and that of winter delayed by 14, 3, and 16 days in Shanghai, Nanjing, and Hefei, respectively.

Regarding to the length of different seasons summarized from the two phenological calendars, it is learned that the length of all the four seasons changed regularly. Among them, spring shortened in Shanghai and Hefei, by 2 days and 6 days, respectively, but without so clear change in Nanjing. Summer lengthened in all the three sites, by 21, 3 , and 9 days in Shanghai, Nanjing, and Hefei, respectively. Overall speaking, autumn lengthened in East China, but with regional differences. Autumn in Nanjing and Hefei lengthened by 1 and 15 days, respectively, while, in Shanghai, it shortened by 2 days. Winter became shorter in all the three sites, shortening by 17, 4, and 18 days in Shanghai, Nanjing, and Hefei, respectively.

\subsection{Changing Trends of the Beginning of Phenological Seasons.} Comparing the changing trend of the beginning time of each season during 1987-1996 to that during 2003-2012, we found out how the season beginning time had been changing (Figure 2).

In the phenological calendar of 1987-1996, the beginning time of spring advanced in Shanghai and Nanjing by 0.04 and 1.02 days/year, respectively, while it delayed in Hefei by 0.54 days/year, with an average advancing trend of 0.17 days/year (Figure 2(a), Table 4). Whereas, in phenological calendar of 2003-2012, beginning time of spring in all 3 stations delayed, by 0.67 days/year in Shanghai, 1.88 days/year in Nanjing, 2.98 days/year in Hefei, respectively, and 1.84 days/year on average.

Figure 2(b) presents that the beginning time of summer delayed in Shanghai by 0.45 days/year while it advanced in Nanjing by 0.99 days/year and that in Hefei delayed by 0.66 days/year and advanced by 0.40 days/year on average in 19871996, and it delayed in all 3 stations, by 0.40 days/year in Shanghai, 0.48 days/year in Nanjing, 0.69 days/year in Hefei, respectively, and 0.52 days/year on average in 2003-2012.

The changing trend of autumn beginning time was advancing in the 3 stations, by 1.17 days/year in Shanghai, 1.56 days/year in Nanjing, 2.96 days/year in Hefei, respectively, and 1.90 days/year on average in 1987-1996 (Figure 2(c)). The overall changing trend in 2003-2012 was 1.01 days/year, indicating a delayed autumn beginning in this period. Regarding the 3 stations, the beginning of autumn in Shanghai and Nanjing delayed by 2.19 and 1.06 days/year while it advanced in Hefei by 0.21 days/year.

Figure $2(\mathrm{~d})$ shows that the winter beginning time advanced in Shanghai and Hefei by 0.54 and 1.82 days/year, respectively, and delayed in Nanjing by 1.32 days/year. On average, the beginning of winter advanced by 0.38 days/year in the phenological calendar of 1987-1996. During the period of 2003-2012, the beginning time of winter in all the 3 stations delayed, by 0.40 days/year in Shanghai, 0.48 days/year in Nanjing, and 0.69 days/year in Hefei, respectively, with an average changing trend of 0.52 days/year. 
TABLE 3: Division of phenological seasons for 1987-1996 and 2003-2012.

\begin{tabular}{|c|c|c|c|c|c|c|c|}
\hline Station & Season & Species & Phenophase & $\begin{array}{c}\text { Beginning } \\
\text { time } \\
(1987-1996)\end{array}$ & $\begin{array}{c}\text { Beginning } \\
\text { time } \\
(2003-2012)\end{array}$ & $\begin{array}{c}\text { Season length } \\
(1987-1996)\end{array}$ & $\begin{array}{c}\text { Season length } \\
(2003-2012)\end{array}$ \\
\hline \multirow{4}{*}{ Shanghai } & Spring & Jasminum nudiflorum & FF & 43 & 40 & 78 & 76 \\
\hline & Summer & Robinia pseudoacacia & $\mathrm{FF}$ & 121 & 116 & 153 & 174 \\
\hline & Autumn & Platanus acerifolia & BLF & 274 & 290 & 64 & 62 \\
\hline & Winter & Magnolia denudata & ELF & 338 & 352 & 70 & 53 \\
\hline \multirow{4}{*}{ Nanjing } & Spring & Salix babylonica & $\mathrm{FL}$ & 54 & 53 & 61 & 61 \\
\hline & Summer & Robinia pseudoacacia & FF & 115 & 114 & 165 & 168 \\
\hline & Autumn & Hibiscus syriacus & $\mathrm{EF}$ & 280 & 282 & 66 & 67 \\
\hline & Winter & Pterocarya stenoptera & ELF & 346 & 349 & 73 & 69 \\
\hline \multirow{4}{*}{ Hefei } & Spring & Ulmus pumila & $\mathrm{FF}$ & 58 & 56 & 58 & 52 \\
\hline & Summer & Robinia pseudoacacia & $\mathrm{FF}$ & 116 & 108 & 155 & 164 \\
\hline & Autumn & Metasequoia glyptostroboides & $\mathrm{BLF}$ & 271 & 272 & 58 & 73 \\
\hline & Winter & Pterocarya stenoptera & ELF & 329 & 345 & 94 & 76 \\
\hline
\end{tabular}

Unit of beginning time: day of the year, DOY.

TABLE 4: Parameters of regression for phenological trends.

\begin{tabular}{|c|c|c|c|c|c|c|c|}
\hline \multirow{2}{*}{ Season } & \multirow{2}{*}{ Station } & \multicolumn{3}{|c|}{ 1987-1996 } & \multicolumn{3}{|c|}{ 2003-2012 } \\
\hline & & Slope (days/year) & $R^{2}$ & $P$ & Slope (days/year) & $R^{2}$ & $P$ \\
\hline \multirow{3}{*}{ Spring } & Shanghai & -0.04 & 0.01 & 0.97 & 0.67 & 0.09 & 0.46 \\
\hline & Nanjing & -1.02 & 0.08 & 0.46 & 1.88 & 0.65 & 0.05 \\
\hline & Hefei & 0.54 & 0.04 & 0.59 & 2.98 & 0.46 & 0.05 \\
\hline \multirow{3}{*}{ Summer } & Shanghai & 0.45 & 0.14 & 0.32 & 0.40 & 0.11 & 0.35 \\
\hline & Nanjing & -0.99 & 0.20 & 0.23 & 0.48 & 0.20 & 0.26 \\
\hline & Hefei & -0.66 & 0.28 & 0.11 & 0.69 & 0.12 & 0.34 \\
\hline \multirow{3}{*}{ Autumn } & Shanghai & -1.17 & 0.16 & 0.50 & 2.19 & 0.54 & 0.02 \\
\hline & Nanjing & -1.56 & 0.10 & 0.41 & 1.06 & 0.11 & 0.39 \\
\hline & Hefei & -2.96 & 0.22 & 0.29 & -0.21 & 0.02 & 0.07 \\
\hline \multirow{3}{*}{ Winter } & Shanghai & -0.54 & 0.04 & 0.56 & 1.70 & 0.65 & 0.01 \\
\hline & Nanjing & 1.32 & 0.15 & 0.35 & 1.85 & 0.44 & 0.07 \\
\hline & Hefei & -1.82 & 0.16 & 0.25 & 0.21 & 0.01 & 0.88 \\
\hline
\end{tabular}

3.3. Variations of Phenophases in Different Seasons. The frequency distribution of seasonal phenophases (Figure 3) can be used to explain the overall variation and characteristics of phenological seasons. At the 3 stations, the majority of phenophases in spring (83.3\% in Shanghai, $72.8 \%$ in Nanjing, and $90.8 \%$ in Hefei) and summer (all in Shanghai, Nanjing, and Hefei) occurred earlier in 2003-2012 than in 19871996 , while the majority of phenophases in autumn $(87.5 \%$ in Shanghai, $77.1 \%$ in Nanjing, and $86.2 \%$ in Hefei) and winter $(100 \%$ in Shanghai, $50 \%$ in Nanjing, and $83.3 \%$ in Hefei) occurred later in 2003-2012 than in 1987-1996. During the period of 2003-2012, phenophases averagely advanced by 7.6, 3.9, and 9.6 days in spring in Shanghai, Nanjing, and Hefei, respectively, compared to the spring phenophases during 1987-1996. Similar changes happened to phenophases in summer, showing by earlier occurrences of 8.1, 4.3, and 7.5 days averagely during 2003-2012 than during 1987-1996 in Shanghai, Nanjing, and Hefei, respectively.
Phenophases in autumn and winter all delayed averagely during the latter period compared to the former. Specifically, autumn phenophases delayed by 7.3, 6.6, and 13.2 days, and winter phenophases delayed by $19.5,1.1$, and 13.5 days on average in Shanghai, Nanjing, and Hefei, respectively. It is indicated that the overall variation of phenophases in each phenological season is similar to that of the beginning time of the corresponding season.

3.4. The Relationship between Phenological Changes and Temperature. Figure 4 exhibits correlations between the beginning of phenological seasons and 60-day preseason mean temperature. Notably, the beginning time of spring and summer shows significant negative correlation with temperature. The significance levels of correlations in Shanghai, Nanjing, and Hefei were $P<0.01, P<0.05$, and $P<0.01$, respectively, for spring and all were $P<0.01$ for summer. The beginning time of autumn and winter shows significant 

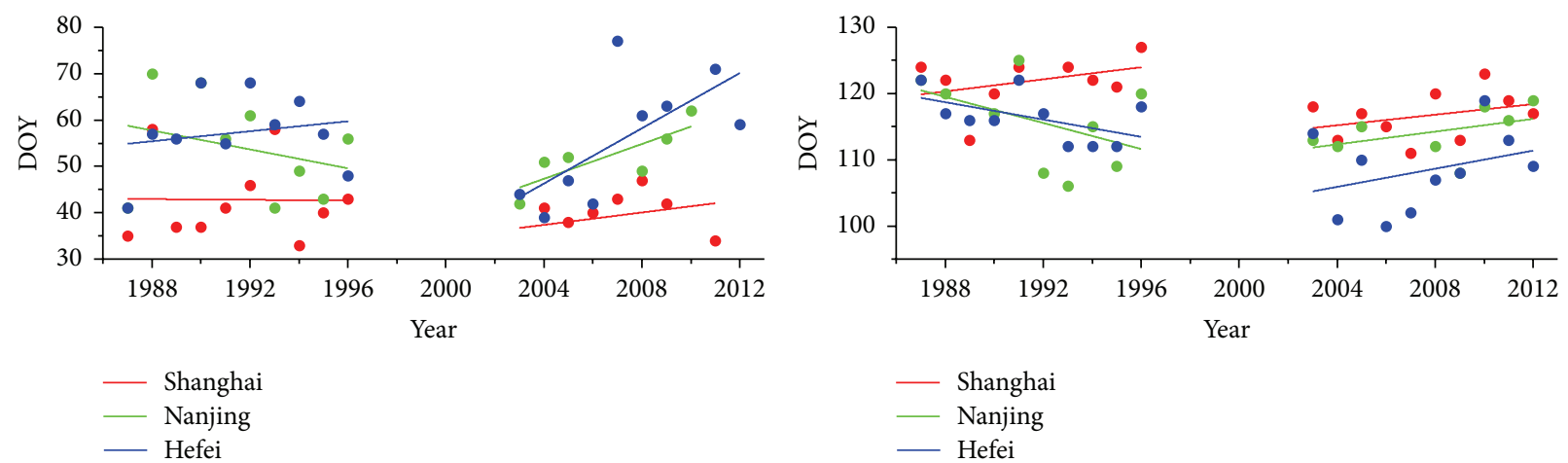

(a)

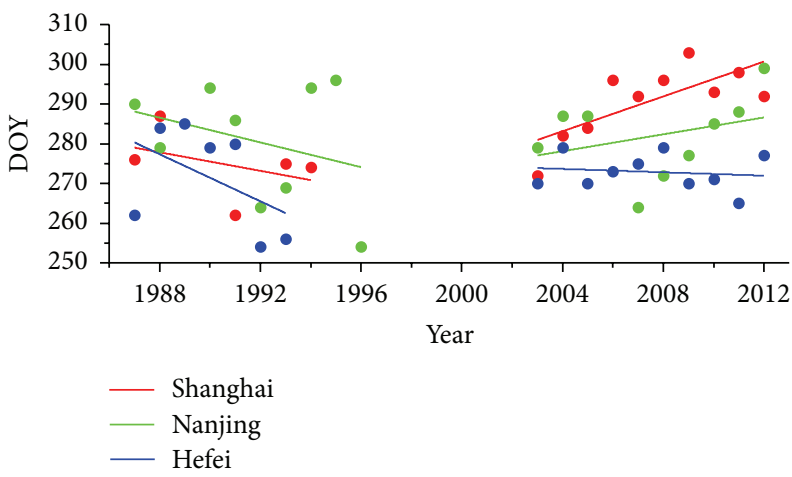

(c)

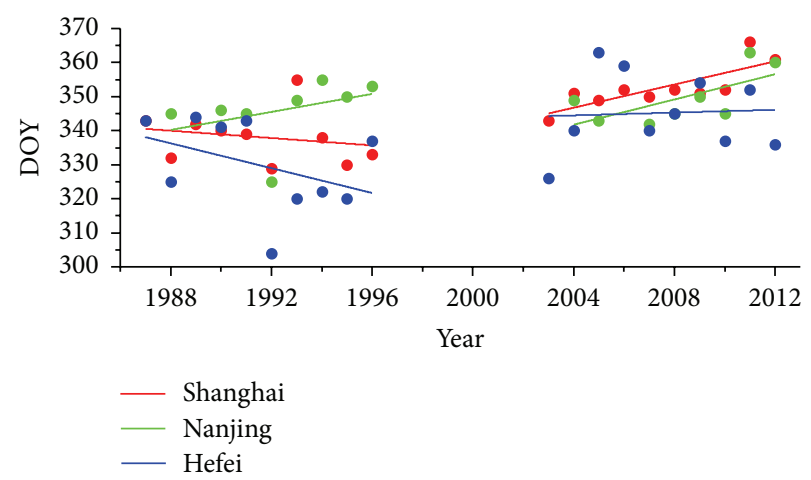

(d)

FIGURE 2: The changing trends in the beginning time of phenological seasons. (a) Spring; (b) summer; (c) autumn; and (d) winter. DOY: day of the year.

positive correlation with temperature. The significance levels of correlations in Shanghai, Nanjing, and Hefei were $P<$ $0.05, P<0.05$, and $P<0.001$, respectively, for autumn, and all were $P<0.05$ for winter. That is, the increase in previous temperature will lead to an advance in spring and summer beginning time and a delay in autumn and winter beginning time and vice versa. The slopes of the linear regression, herein, represent the sensitivities of the beginning of phenological seasons to temperature. The sensitivities ranged from -6.49 to -6.55 days $/{ }^{\circ} \mathrm{C}$ in spring, -3.65 to -5.02 days $/{ }^{\circ} \mathrm{C}$ in summer, 8.13 to 10.27 days $/{ }^{\circ} \mathrm{C}$ in autumn, and 4.76 to 10.00 days $/{ }^{\circ} \mathrm{C}$ in winter.

\section{Discussion and Conclusion}

4.1. Discussion. The compilation of phenological calendars by applying phenological observation data from CPON was very unique in China. The systematical results were published in 1986 and 1987 [8, 9]. They were used for instruction in agricultural activities in the past by arranging cultivation times for crops and providing references for pest control [1]. This study developed a new approach in the application of phenological calendar in the field of climate changes. As phenological seasons defined by phenological calendar were with good geographical representation and described the relatively stable phenophases during a certain period of time and the sequence of these phenophases was usually put in regular order, they were of high significance when used in the comparison of phenophases between different time periods. Therefore, the phenophase changes in each season of a year during different time periods were indicated very evidently in this study. Besides, changes of length for phenological seasons together with the phenological sensitivities to temperature in different time period were also studied very sufficiently.

Another important finding of this study is that the spring phenological sensitivity to temperature was from -6.49 to -6.55 days $/{ }^{\circ} \mathrm{C}$ in East China. The result of a former study shows that the phenological sensitivities to temperature in Northeast China were between -1.99 and -6.18 days $/{ }^{\circ} \mathrm{C}$, with an average of -3.00 days $/{ }^{\circ} \mathrm{C}[13]$, which was almost half of our result. It further demonstrated that the phenological sensitivities to temperature were greater at lower latitudes than those at higher latitudes [23, 24]. This discrepancy can be possibly explained by spring GDD (Growing Degree Days) Models [24]. Owing to the longer duration of heat accumulation, the plants in warmer areas receive greater extra heat accumulation than those in colder areas with the temperature increase by the same amount, and this leads to the plant phenophases more sensitive to temperature at lower latitudes.

This is the beginning of studying phenological changes in subtropical areas in China and such conclusions remain to be strengthened by further studies in the future.

4.2. Conclusion. With phenological data from China Phenological Observation Network of Chinese Academy of Sciences 

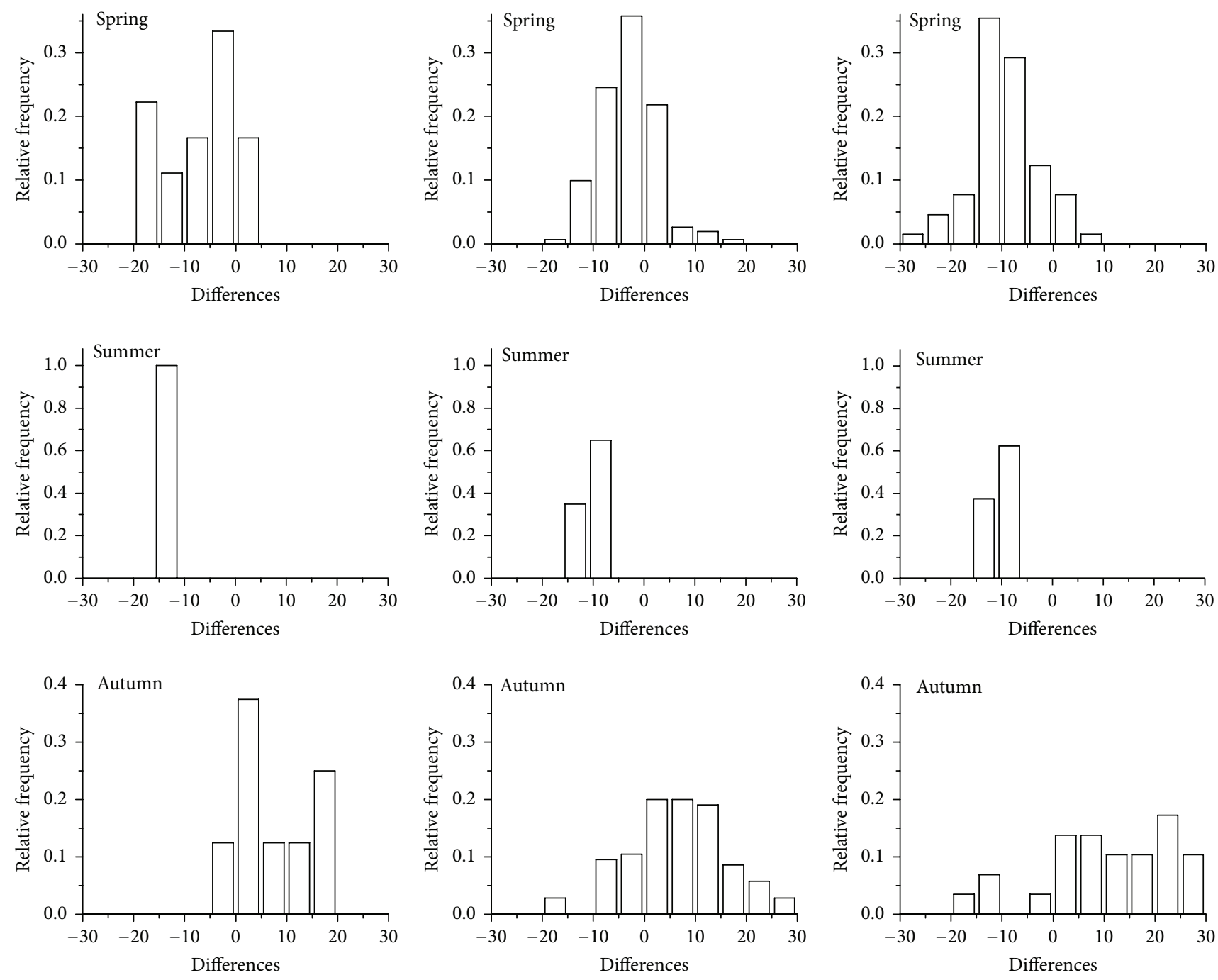

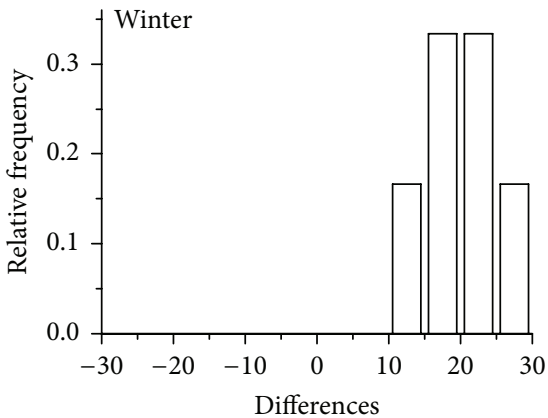

(a)

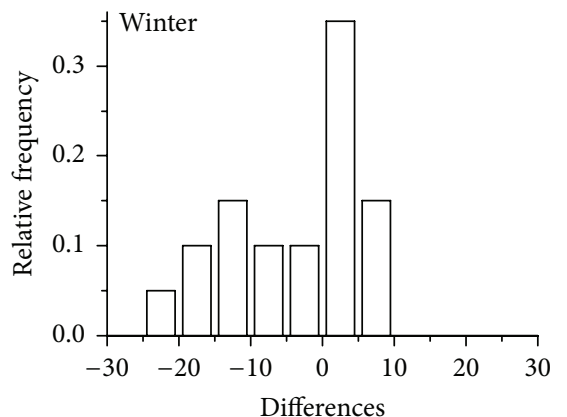

(b)

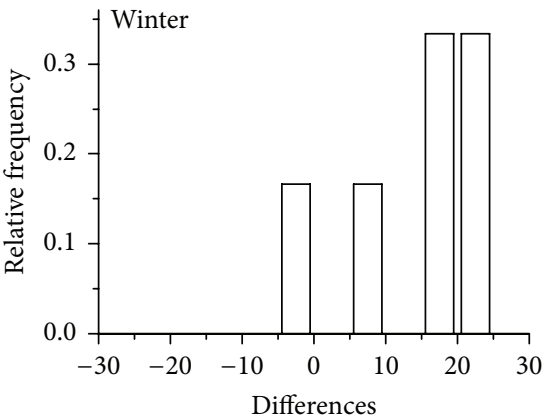

(c)

Figure 3: Frequency distribution of the differences in mean phenological dates between the phenological calendar of 1987-1996 and 20032012. The columns stand for Shanghai (a), Nanjing (b), and Hefei (c), respectively. 


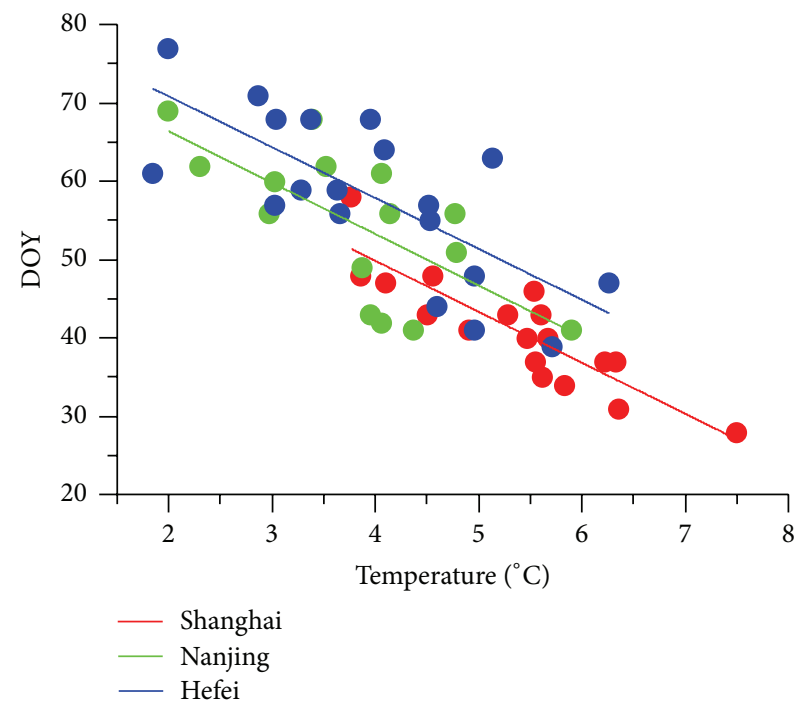

(a)

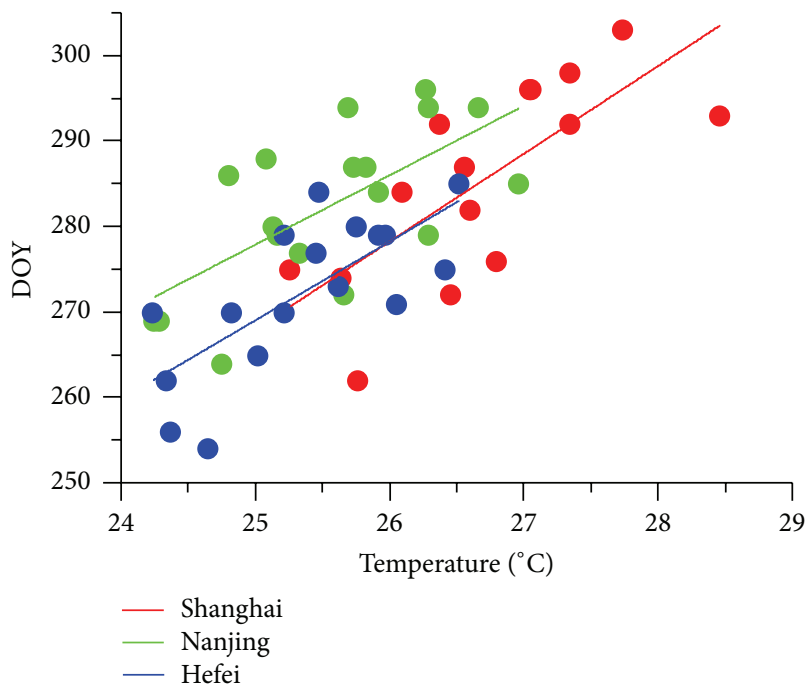

(c)

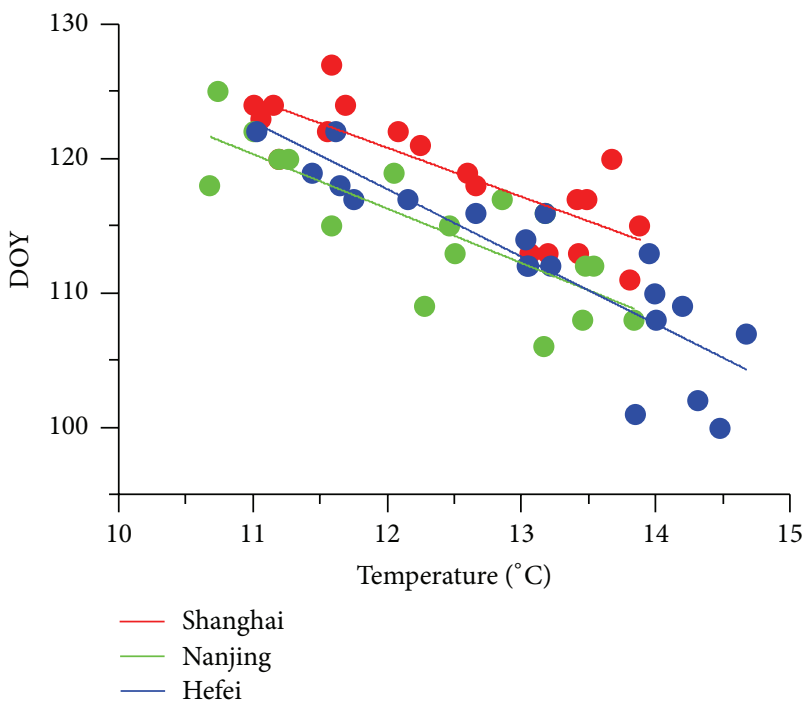

(b)

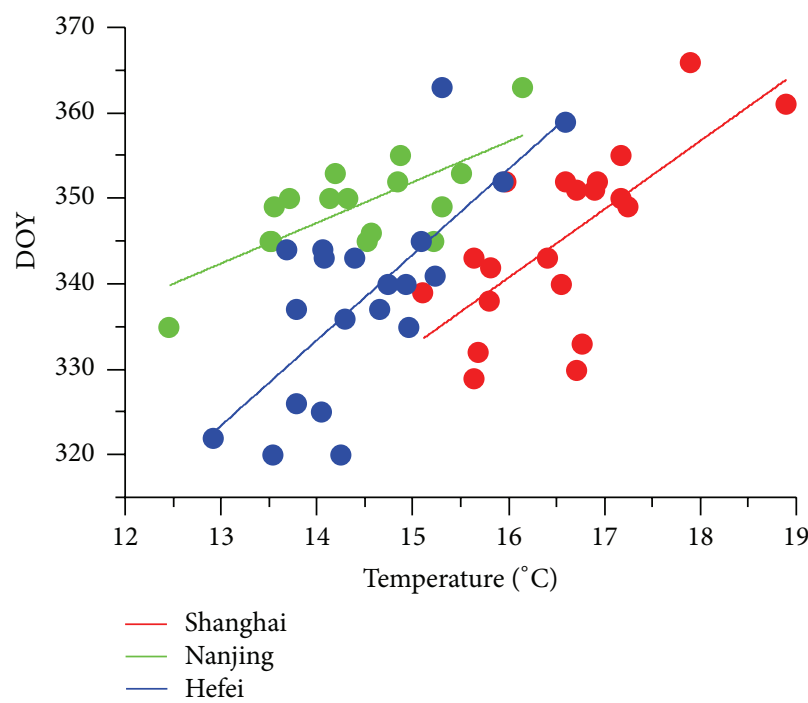

(d)

FIGURE 4: Linear correlation analysis between the beginning time of phenological season and the mean temperature of the previous 60 days in 1987-2012. (a) Spring, Shanghai: $y=-6.51 x+75.86\left(R^{2}=0.77, P<0.01\right)$; Nanjing: $y=-6.55 x+79.45\left(R^{2}=0.47, P<0.05\right)$; and Hefei: $y=-6.49 x+83.79\left(R^{2}=0.53, P<0.01\right)$. (b) Summer, Shanghai: $y=-3.65 x+164.59\left(R^{2}=0.67, P<0.01\right)$; Nanjing: $y=-4.06 x+164.94$ $\left(R^{2}=0.64, P<0.01\right)$; and Hefei: $y=-5.02 x+177.93\left(R^{2}=0.77, P<0.01\right)$. (c) Autumn, Shanghai: $y=10.27 x+11.22\left(R^{2}=0.55\right.$, $P<0.05)$; Nanjing: $y=8.13 x+74.72\left(R^{2}=0.44, P<0.05\right)$; and Hefei: $y=9.22 x+38.44\left(R^{2}=0.53, P<0.001\right)$. (d) Winter, Shanghai: $y=8.00 x+212.65\left(R^{2}=0.48, P<0.05\right)$; Nanjing: $y=4.76 x+280.48\left(R^{2}=0.54, P<0.05\right)$; and Hefei: $y=10.00 x+193.34\left(R^{2}=0.53\right.$, $P<0.05)$.

and the meteorological data from China Meteorological Administration, this paper reveals the characteristics of variations between the phenological calendar for 2003-2012 and that for 1987-1996 and the response of phenophases to climate change. The conclusions are as follows:

(1) The beginning of spring and summer in East China was earlier and the beginning of autumn and winter was later in 2003-2012 than in 1987-1996. Summer lengthened by 21,3 , and 9 days, and winter shortened by $17,4,18$, days, respectively, in Shanghai, Nanjing, and Hefei.
(2) The beginning time of all four seasons showed advancing trends of 0.17 days/year in spring, 0.40 days/year in summer, 1.90 days/year in autumn, and 0.38 days/year in winter during 1987-1996, while the beginning time of all four seasons showed delaying trends of 1.84 days/year in spring, 0.52 days/year in summer, 1.01 days/year in autumn, and 0.52 days/year in winter during 2003-2012.

(3) Most spring and summer phenophases occurred earlier and most autumn and winter phenophases occurred later during 2003-2012 than during 19871996, indicating that the advancing and delaying 
of mean phenophases were in accordance with the change of the beginning time of the corresponding phenological season.

(4) The beginning time of spring and summer shows significant negative correlation with temperature, while the beginning time of autumn and winter shows significant positive correlation with temperature. The phenological sensitivities to temperature ranged from -6.49 to -6.55 days $/{ }^{\circ} \mathrm{C}$ in spring, -3.65 to -5.02 days $/{ }^{\circ} \mathrm{C}$ in summer, 8.13 to 10.27 days $/{ }^{\circ} \mathrm{C}$ in autumn, and 4.76 to 10.00 days $/{ }^{\circ} \mathrm{C}$ in winter.

\section{Competing Interests}

The authors declare that there is no conflict of interests regarding the publication of this paper.

\section{Acknowledgments}

This study is supported by National Key Basic Research Program of China (Grant no. 2012CB955304), Major National Research Program of Scientific Instruments from National Natural Science Foundation (Grant no. 41427805), and Strategic Priority Research Program of the Chinese Academy of Sciences (Grant no. XDA05090301).

\section{References}

[1] K. Z. Zhu and M. W. Wan, Phenology, Science Press, Beijing, China, 1973.

[2] M. D. Schwartz, Phenology: An Integrative Environmental Science, Kluwer Academic, Dordrecht, The Netherlands, 2013.

[3] F. Zwiers and G. Hegerl, "Climate change: attributing cause and effect," Nature, vol. 453, no. 7193, pp. 296-297, 2008.

[4] T. L. Root, J. T. Price, K. R. Hall, S. H. Schneider, C. Rosenzweig, and J. A. Pounds, "Fingerprints of global warming on wild animals and plants," Nature, vol. 421, no. 6918, pp. 57-60, 2003.

[5] R. Ahas, J. Jaagus, and A. Aasa, "The phenological calendar of Estonia and its correlation with mean air temperature," International Journal of Biometeorology, vol. 44, no. 4, pp. 159$166,2000$.

[6] A. Menzel, N. Estrella, and P. Fabian, "Spatial and temporal variability of the phenological seasons in Germany from 1951 to 1996," Global Change Biology, vol. 7, no. 6, pp. 657-666, 2001.

[7] G. D. Yang, The Phenological Calendar of Beijing and Its Application, Capital Normal University Press, Beijing, China, 1995.

[8] M. W. Wan, Selected Phenological Calendars of China, Science Press, Beijing, China, 1986.

[9] M. W. Wan, Continuation of Phenological Calendars of China, Science Press, Beijing, China, 1987.

[10] H. J. Wang, J. H. Dai, and Q. S. Ge, "The spatiotemporal characteristics of spring phenophase changes of Fraxinus chinensis in China from 1952 to 2007," Science China Earth Sciences, vol. 55, no. 6, pp. 991-1000, 2012.

[11] E. E. Cleland, I. Chuine, A. Menzel, H. A. Mooney, and M. D. Schwartz, "Shifting plant phenology in response to global change," Trends in Ecology \& Evolution, vol. 22, no. 7, pp. 357365, 2007.
[12] S. Y. Zhong, Q. S. Ge, J. Y. Zheng et al., "Variations of main phenophases of natural calendar and phenological seasons in Beijing for the last 30 years,' Chinese Journal of Plant Ecology, vol. 36, no. 12, pp. 1217-1225, 2012.

[13] Y. J. Xu, J. H. Dai, H. J. Wang et al., "Variations of main phenophases of natural calendar and analysis of responses to climate change in Harbin in 1985-2012," Geographical Research, vol. 34, no. 9, pp. 1662-1674, 2015.

[14] X. Q. Fang and W. H. Yu, "Progress in the studies on the phenological responding to global warming," Advance in Earth Sciences, vol. 17, no. 5, pp. 714-719, 2002.

[15] Q. S. Ge, H. J. Wang, T. Rutishauser, and J. Dai, "Phenological response to climate change in China: a meta-analysis," Global Change Biology, vol. 21, no. 1, pp. 265-274, 2015.

[16] J. Dai, H. Wang, and Q. Ge, "Multiple phenological responses to climate change among 42 plant species in Xian, China," International Journal of Biometeorology, vol. 57, no. 5, pp. 749758,2013

[17] D. W. Wolfe, M. D. Schwartz, A. N. Lakso, Y. Otsuki, R. M. Pool, and N. J. Shaulis, "Climate change and shifts in spring phenology of three horticultural woody perennials in northeastern USA," International Journal of Biometeorology, vol. 49, no. 5, pp. 303-309, 2005.

[18] A. Menzel, T. H. Sparks, N. Estrella et al., "European phenological response to climate change matches the warming pattern," Global Change Biology, vol. 12, no. 10, pp. 1969-1976, 2006.

[19] M. D. Schwartz, R. Ahas, and A. Aasa, "Onset of spring starting earlier across the Northern Hemisphere," Global Change Biology, vol. 12, no. 2, pp. 343-351, 2006.

[20] C. Defila and B. Clot, "Phytophenological trends in Switzerland," International Journal of Biometeorology, vol. 45, no. 4, pp. 203-207, 2001.

[21] C. Parmesan and G. Yohe, "A globally coherent fingerprint of climate change impacts across natural systems," Nature, vol. 421, no. 6918 , pp. 37-42, 2003.

[22] J.-Y. Fang, Y.-C. Song, H.-Y. Liu, and S.-L. Piao, "Vegetationclimate relationship and its application in the division of vegetation zone in China," Acta Botanica Sinica, vol. 44, no. 9, pp. 1105-1122, 2002.

[23] Y. Y. Xie, P. L. Lu, and Q. Yu, "Sensitivity of leaf unfolding date for woody plant to temperature variability in spring in China's eastern monsoonal region," Chinese Journal of Agrometeorology, vol. 31, no. 4, pp. 495-500, 2010.

[24] J. H. Dai, H. J. Wang, and Q. S. Ge, "The spatial pattern of leaf phenology and its response to climate change in China," International Journal of Biometeorology, vol. 58, no. 4, pp. 521528, 2014. 

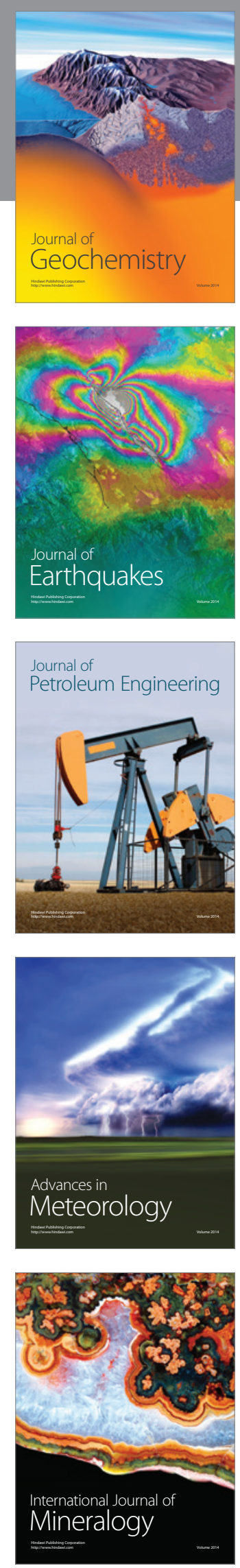
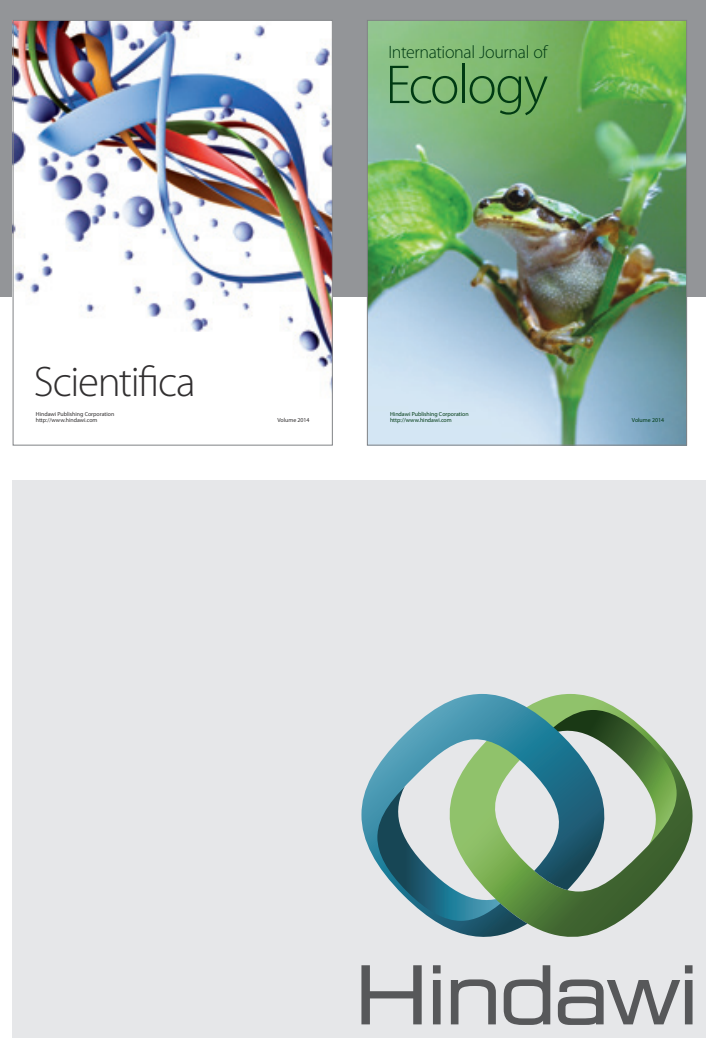

Submit your manuscripts at

http://www.hindawi.com
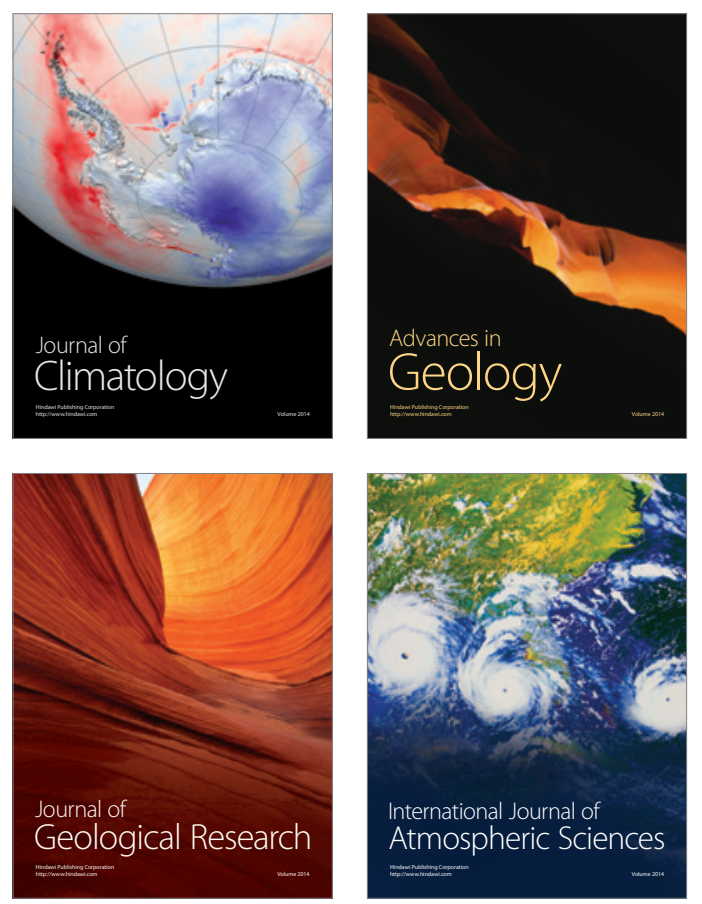

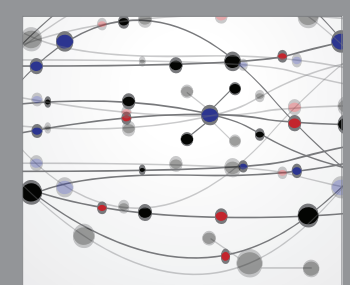

The Scientific

\section{World Journal}
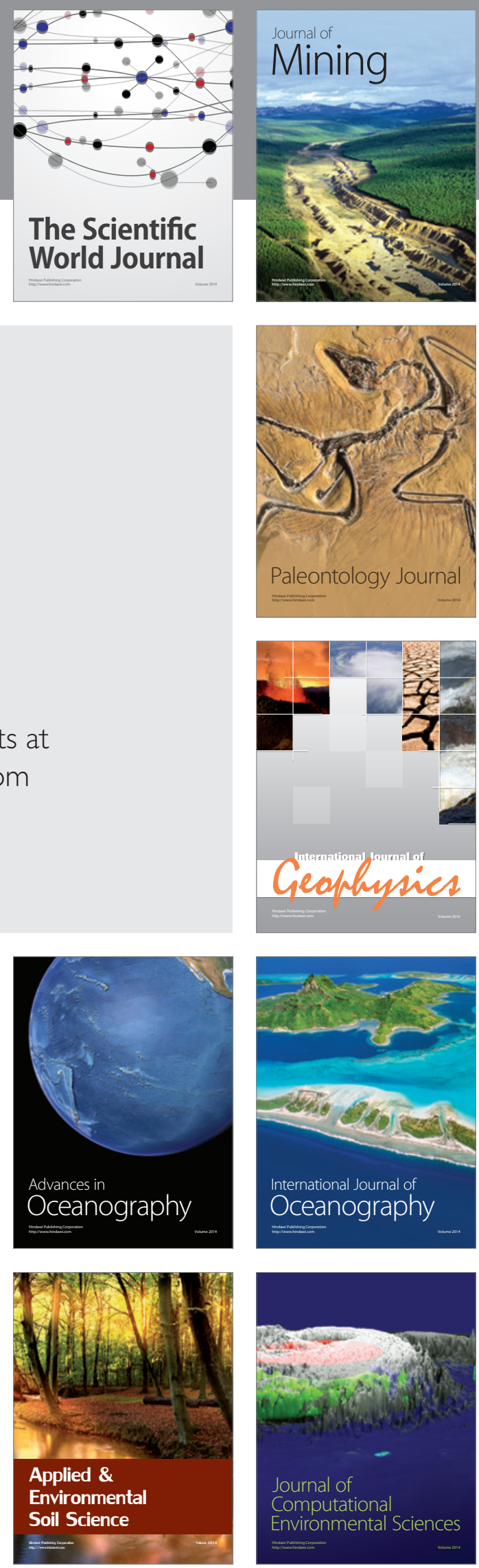